DOI: $10.26754 /$ ojs_aem/aem.2019304635

Recibido: $20 / 02 / 2020$

Aceptado: 26/04/2020
Aragón en la Edad Media

30 (2019) 121-142

e-ISSN: 2387-1377

ISSN: 0213-2486

\title{
DEHESAS ANTIGUAS, PASTORES FORANOS Y JURISDICCIONES CUESTIONADAS: CONFLICTIVIDAD GANADERA A FINALES DE LA EDAD MEDIA EN LA COMUNIDAD DE ALDEAS DE DAROCA
}

\author{
ANCIENT PASTURES, FOREIGN SHEPHERDS AND CONTESTED JURISDICTIONS: \\ LIVESTOCK CONFLICT IN THE LATE MIDDLE AGES \\ IN THE COMUNIDAD DE ALDEAS DE DAROCA
}

Lidia C. Allué ANDRÉS y María Luz RodRIGO-ESTEVAN Université Toulouse 2 Jean Jaurès / Universidad de Zaragoza lydiaallue@gmail.com / lrodrigo@unizar.es

Resumen: Desde la expansión del Reino de Aragón hacia el sur a partir del siglo XI, los ganaderos fueron colonizando y poniendo en cultivo las nuevas tierras conquistadas a los musulmanes. La orografía del reino favoreció la trashumancia entre las regiones del valle del Ebro, donde los ganados permanecían en invierno y los ricos pastos de verano de los Pirineos y el Sistema Ibérico. Los numerosos privilegios reales que desde el siglo XIII obtuvo la Casa de Ganaderos de Zaragoza entraron pronto en conflicto con los de la Comunidad de aldeas de Daroca, dando lugar a innumerables y costosos pleitos. La sentencia arbitral de 1501 fue un intento infructuoso de poner paz entre dos
Abstract: Since the expansion of the Kingdom of Aragon towards the South from the $11^{\text {th }}$ century, cattle breeders colonised and cultivated the new lands conquered from the Muslims. The kingdom's orography favoured transhumance between the regions of the Ebro Valley, where the cattle remained in winter and the rich summer pastures of the Pyrenees and the Iberian System. Since the $13^{\text {th }}$ century, the advantageous privileges of the Casa de Ganaderos de Zaragoza soon came into conflict with those of the Comunidad de aldeas de Daroca, resulting in countless and costly lawsuits. The arbitration award of 1501 was an unsuccessful attempt to bring 
poderosas instituciones deseosas de defender sus derechos a toda costa.

Palabras clave: Comunidad de aldeas de Daroca, Casa de Ganaderos de Zaragoza, trashumancia, sentencia arbitral, conflictos ganaderos, siglo XV, Reino de Aragón. peace between two powerful institutions eager to defend their rights at all costs.

Key words: Comunidad de aldeas de Daroca, Casa de Ganaderos de Zaragoza, transhumance, arbitration award, livestock conflicts, $15^{\text {th }}$ century, Kingdom of Aragon.

\section{Introducción ${ }^{1}$}

La expansión del reino de Aragón hacia el sur durante los siglos XI y XII fue efectiva gracias no solamente a las tropas que lucharon contra el enemigo y protegieron la frontera, sino también a los ganaderos - venidos sobre todo de los Pirineos- y colonos que se desplazaron hasta las nuevas tierras y las pusieron en explotación. Con la incorporación de nuevos espacios, las posibilidades de llevar los ganados a pacer a lugares cada vez más alejados posibilitó la trashumancia. Esta actividad se vio favorecida por la diversidad orográfica del reino, con áreas elevadas de montaña, ricas en pastos de verano y valles en los que poder apacentar a los animales en invierno (fig. 1).

Dentro de Aragón se distinguen dos zonas especialmente interesantes para esta actividad, separados por el valle del Ebro: los Pirineos y el Sistema Ibérico. Puesto que en esta región los suelos no son especialmente fértiles - salvo allá donde hay fuentes de agua - ni los pastos abundantes, los ganaderos zaragozanos de la Cofradía de San Simón y Judas enviaron sus ganados a estas dos zonas, practicando lo que se denomina en la historiografía sobre el tema como 'trashumancia corta', con desplazamientos no superiores a $250 \mathrm{~km}$ (fig. 2).

El uso de los pastos, hierbas y aguas, sumado al auge de la ganadería, ${ }^{2}$ dieron como resultado la aparición de numerosos conflictos entre concejos,

1 Nuestro reconocimiento con este artículo a quien ha sido colega departamental así como profesor e impulsor de una trayectoria investigadora sobre los despoblados bajomedievales de la Comunidad de aldeas de Daroca. Gracias por todas las horas de debates, discusiones y desaliento compartidas en este proyecto doctoral. Pronto brindaremos juntos por los feluses de Mercadal.

2 Hace ya 30 años, M. ${ }^{\mathrm{a}}$ Isabel Falcón llamaba la atención sobre el vacío historiográfico referente a la ganadería aragonesa (Falcón, 1982), que comenzó a paliarse con las ediciones de Ángel Canellas (1982; 1988) de documentación del archivo de Casa de Ganaderos. A pesar de que tímidamente van apareciendo nuevas investigaciones sobre determinadas regiones, como las de Albarracín (Berges, 2004; 2006; 2009) y Teruel (Abad, 2004), a día de hoy seguimos sin tener una síntesis de la actividad ganadera en Aragón durante los siglos medievales. 

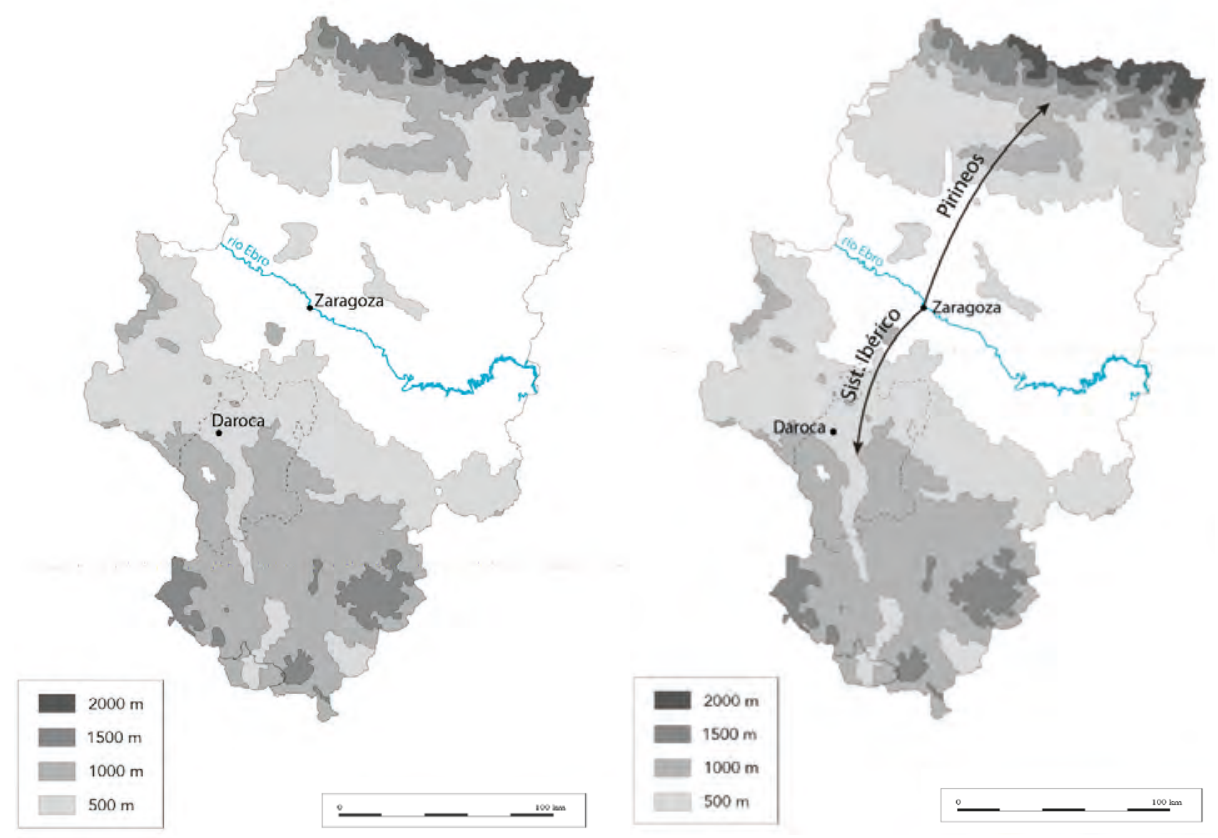

Figura 1. Orografía de Aragón. ( Lidia C. Allué Andrés. En línea discontinua se marca la extensión de la Comunidad de aldeas de Daroca.

Figura 2. Movimientos trashumantes de la cabaña ganadera zaragozana. (๑) Lidia C. Allué Andrés.

señoríos e instituciones, especialmente a partir del siglo XIV. La que más pleitos generó fue, sin lugar a dudas, la Casa de Ganaderos de Zaragoza, cuyos pastores provocaban antipatía allá donde fueran debido a unos ventajosos privilegios que acumularon a lo largo de siglos y que amenazaban con esquilmar los recursos de los habitantes del resto de poblaciones y señoríos.

Dentro de las cuatro comunidades de aldeas existentes en Aragón, la de Daroca es la que sostuvo más litigios con la cofradía de ganaderos zaragozana. Su clima árido y sus suelos mayoritariamente desfavorables para las actividades agrícolas impulsaron el desarrollo de la ganadería desde la conquista misma de Daroca en 1120. Sus abundantes pastos, aunque de menor calidad que los de los Pirineos, la convertían en una región muy atractiva a los ojos de los zaragozanos quienes, debido al constante aumento de su cabaña, se vieron en la imperiosoa necesidad de buscar amplias zonas en las que alimentar a sus 
animales. Por su parte, uno de los pilares económicos de la comunidad darocense fue la actividad ganadera, especialmente la ovina, por lo que no es de extrañar que defendiesen sus pastos y hierbas con uñas y dientes de los zaragozanos. ${ }^{3}$ Los conflictos fueron tan abundantes y tan costosos que ambas instituciones, junto con Longares y la Comunidad de aldeas de Albarracín, recurrieron al rey para que promulgase una sentencia arbitral en 1501. Como era de esperar, dicha sentencia no fue respetada y los conflictos se sucedieron hasta la desaparición de la Comunidad de aldeas de Daroca en 1837 (Diarte, 1993).

\section{Casa de Ganaderos de Zaragoza versus Comunidad de aldeas de Daroca: dos instituciones en constante lucha}

Tanto la Comunidad de aldeas de Daroca como la Casa de Ganaderos de Zaragoza son dos instituciones bien conocidas a través de la historiografía publicada, aunque sin duda la primera ha sido menos estudiada ${ }^{4}$ A continuación, analizamos con brevedad algunos puntos clave necesarios para comprender los motivos de la confrontación que motivó la promulgación de la sentencia arbitral de 1501.

\subsection{La Casa de Ganaderos de Zaragoza}

Tras la conquista de Zaragoza en diciembre de 1118, Alfonso I concedió un fuero a la ciudad en el que se establecía que los zaragozanos - no solamente los ganaderos - podían utilizar libremente los montes del término para apacentar sus ganados, obtener leña menuda, extraer piedra, hacer carbón y realizar otros aprovechamientos a la par que eran declarados exentos del pago del herbático —o herbaje - y de la lezda. Diez años más tarde, en febrero de 1129, los zaragozanos recibieron otro fuero que incluía el célebre Privilegio de Veinte o Tortum per tortum gracias al cual, en caso de recibir cualquier tipo de agravio dentro de las tierras reales, podían tomar prenda y exigir reparación

3 Tanto la documentación archivística (ordenanzas, privilegios, pleitos, sentencias arbitrales...) como los restos materiales (parideras, abrevaderos, balsas) y la pervivencia secular de la función ganadera de los bienes comunales, constatan la intensa actividad ganadera en el territorio analizado (Diarte, 1993: 178-206).

4 Para profundizar sobre la primera, ver Canellas, 1982 y 1988; Fernández, 1993; Gerbet: 2003; Pascua, 2012. Para la segunda, se pueden consultar los trabajos de Corral, 1987; Diarte, 1993; y Allué, 2018. 
del acusado en Zaragoza u otro sitio. En este fuero se encuentran, además, los antecedentes de la denominada pastura universal, pues contemplaba la concesión del derecho a que el ganado zaragozano pudiese pacer en cualquier monte propiedad del rey situado dentro del término de la ciudad, así como a beneficiarse de todos los derechos derivados que este privilegio llevaba anexo tales como el uso de abrevaderos reales o la recogida de leña, entre otros. ${ }^{5}$

Consciente de su falta de apoyos dentro de la nobleza y de la turbulenta situación política en torno a su persona, el joven monarca Jaime I decidió ganarse a base del reconocimiento de privilegios el afecto y apoyo de diversos sectores sociales. Y uno de los primeros fue el de los ganaderos de Zaragoza. ${ }^{6}$ Con tan sólo diez años de edad, en 1218, el rey otorgó a este colectivo el derecho a tener jurisdicción propia y un juez con competencia civil y criminal para sustanciar cualquier pleito en el que se vieran envueltos los rebaños de la ciudad, sus dueños o sus pastores. En 1229 Jaime I les concedió otro privilegio en el que se nombra por primera vez de manera expresa la Cofradía de San Simón y Judas, popularmente conocida como Casa de Ganaderos de Zaragoza (Canellas, 1988: docs. 4-5). Sucesivos privilegios favorecieron el poder y beneficios de los zaragozanos, como por ejemplo en 1235, cuando el privilegio de la pastura universal se amplió y se extendió a todos los montes y a toda la tierra del rey, es decir, mucho más allá del término de Zaragoza. No obstante, había dos dehesas antiguas que el monarca se guardaba para sí: la de Sigena y la Retuerta de Pina. (Canellas, 1972: I, doc. 60) Tampoco podían los zaragozanos penetrar en los boalares o dehesas boyales - reservadas para el apacentamiento de los animales de tiro- ni en los montes vedados ${ }^{7}$ o cerrados existentes antes de la concesión de la pastura universal (Canellas, 1988: doc. 7).

Como era de esperar, todas estas ventajas no gustaron nada a las localidades dependientes del rey, sobre todo porque se rompía con la antiquísima tradición de la alera foral. Este término aparece por primera vez en el Fuero de Jaca (1077) y supone el aprovechamiento de los pastos de dos localidades

5 Sobre el Privilegio de los Veinte y sus referencias al ganado y los aprovechamientos del monte: GarcíaEdo, 2016; Agudo, 2009; una visión actualizada desde la historia del derecho de la pastura universal y la alera foral es recogida en Pérez-Soba y Solá, 2004.

6 Rodrigo, 2009. Entre la producción bibliográfica surgida en torno al 800 aniversario del nacimiento de Jaime I, resulta de especial interés el monográfico coordinado por Esteban Sarasa Sánchez (2009).

7 Los vocablos 'vedado' y 'dehesa' aluden a la idea general de monte cerrado, esto es, de lugares acotados para aprovechamiento ganadero, que pueden ser comunales o de propiedad privada. Por otro lado, todas las tierras de labor, una vez recogida la cosecha, se convertían en campos abiertos en los que el ganado podía pastar libremente. (Líbano y Villacorta, 2013: 58-61). 
vecinas por los pastores de ambas, poniendo como única condición que el ganado pueda ir y volver en el mismo día y que fuese, como máximo, hasta las eras del pueblo vecino; ${ }^{8}$ de ahí la expresión «de sol a sol y de era a era». A partir de 1235 los zaragozanos podían explotar los pastos de cualquier lugar de realengo, pero los de la ciudad eran de uso exclusivo de sus habitantes, rompiéndose así la reciprocidad.

\subsection{La Comunidad de aldeas de Daroca}

Daroca fue tomada en 1120 y se le concedió un extenso territorio que fue la base sobre la que se conformó la Comunidad de aldeas de Daroca a partir de 1248 (fig. 3). Esta institución —y distrito jurisdiccional — es la más antigua de las cuatro comunidades de aldeas que existieron en Aragón y acabó desapareciendo por una Orden Real en 1837. Localizada en el suroeste del reino, estuvo situada en la frontera con Castilla, lo cual favoreció, entre otros muchos aspectos, las razzias de ganado tanto por parte de los darocenses como de los castellanos.

La accidentada geografía y un clima extremo, sumado a la pobreza general de sus suelos y a otras variables, configuraron unos patrones de poblamiento caracterizados por aldeas de pequeño tamaño muy cercanas las unas a las otras, sin grandes centros de población que fuesen capaces de organizar mínimamente el territorio. El hecho de que parte de los repobladores fuesen ganaderos también favoreció el pequeño tamaño de los lugares. Esta actividad requiere de grandes superficies de tierra destinadas al alimento de los animales, por lo que en caso de haber muchos habitantes en un lugar se rompería el equilibrio entre las parcelas dedicadas al alimento de los lugareños y las reservadas a los rebaños. ${ }^{9}$

A partir del siglo XIV comenzaron a ser abundantes los pleitos entre localidades vecinas por los términos de cada una. No hay que perder de vista que, en el fondo, lo que estaba detrás de esos conflictos era el aprovechamiento de tierras destinadas a pastos, leñas, caza... (Fernández, 1993: 23) ya que en ese momento se alcanzó el máximo demográfico de la comunidad darocense y sus habitantes necesitaban más superficie para cultivar cereales y apacentar gana-

Pérez-Soba y Solá, 2004. Esta zona de pastos comunes situada en el límite de dos o más aldeas se conoce como ademprivio o ademprio (Líbano y Villacorta, 2013: 58).

9 Una comparativa entre los diversos modelos de poblamiento de las comunidades aldeanas de la Extremadura aragonesa, en Utrilla, 2004: 434. 


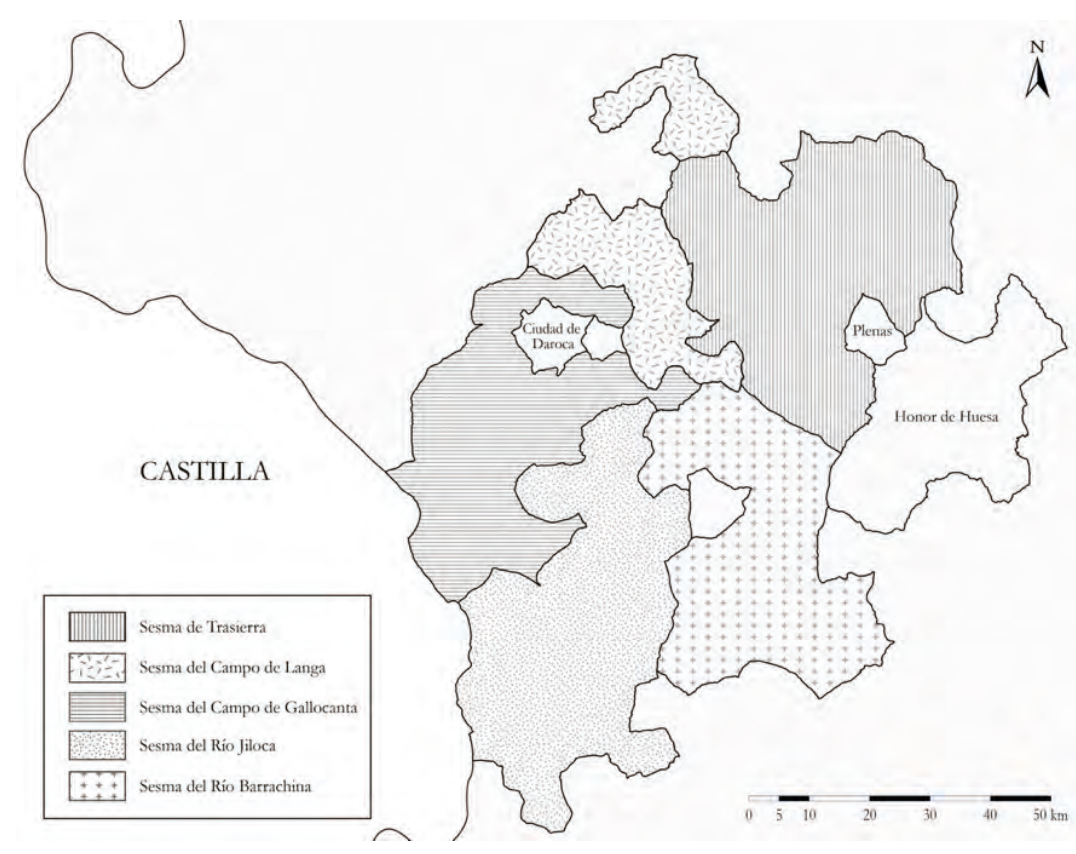

Figura 3. Las sesmas de la Comunidad de aldeas de Daroca durante la Edad Media. (C) Lidia C. Allué Andrés (2018).

do. Especialmente para esto último, puesto que la actividad ganadera fue un vector económico muy importante en esta región.

Al contrario de lo que se podría pensar, el importante descenso demográfico originado por las crisis bajomedievales — con la Peste Negra y la Guerra de los Dos Pedros a la cabeza - no alivió estas disputas, antes bien las acrecentó. Pero no tanto entre aldeas vecinas, sino entre la Comunidad de aldeas de Daroca y la Casa de Ganaderos de Zaragoza. El abandono de numerosas parcelas que habían estado destinadas a la agricultura, sumado a una importante reconfiguración de los patrones de poblamiento, ${ }^{10}$ hizo que los zaragozanos viesen esta tierra como muy atractiva, dada la amplia disponibilidad de pastos nuevos.

Desde la concesión del fuero de Daroca en 1142 se intentó mantener la paz entre agricultores y ganaderos, estableciendo la obligación de los primeros de

10 Algo más del 20\% de los pueblos existentes antes de 1348 desaparecieron antes de acabar el siglo XV, convirtiendo sus antiguos términos en pardinas, de las cuales se hablará más adelante (Allué, 2018). 
vallar sus parcelas para impedir que las bestias pudiesen entrar en ellas y estropear las cosechas. Este mismo deseo de evitar conflictos entre unos y otros se ve en las primeras ordenanzas de la Comunidad, sancionadas por Jaime I en 1256 (Campillo, 1915, doc. 11). Este rey, que también buscó apoyo entre las ciudades y comunidades de aldeas para defenderse de los nobles levantiscos, fue precisamente el que les otorgó el privilegio de 1248 que supone el hito fundacional de la comunidad darocense. ${ }^{11}$

En 1270 se reguló por escrito ${ }^{12}$ el aprovechamiento de las dehesas y boalares, cuya creación o, si era el caso, ampliación, se dejó en manos de los denominados sesmeros. ${ }^{13}$ Con tal autorización, la Comunidad, a través de sus representantes territoriales, podía crear sus propias dehesas y boalares, cuyo uso y disfrute quedaba reservado a los habitantes de la aldea en la que se situaban. A modo de ejemplo, la documentación atestigua cómo quedaron delimitadas las dehesas de Lagunas en $1328,{ }^{14}$ de Used en $1333^{15}$ o de Caminreal y Torrijo del Campo en $1338,{ }^{16}$ en un período cronológico, como ya hemos señalado, en los que la población era numerosa y los problemas por el acceso a los pastos iban en aumento. ${ }^{17}$

Aunque los sesmeros quedaron facultados para delimitar dehesas y boalares, era necesario que el rey confirmase estas acciones para considerarlas legales. A fin de cuentas, la comunidad estaba sometida a los Fueros generales que garantizaban al rey esta potestad, a la cual nunca renunció la monarquía, muy consciente de los conflictos y problemáticas interterritoriales que tal cesión podía acarrear. Por ello, en 1326, Jaime II no tuvo ninguna duda al decidir considerar nulas las dehesas creadas varios años antes en algunas aldeas darocenses y que no habían sido confirmadas por el monarca (Corral, 1987: 210).

11 Archivo de la Corona de Aragón (ACA), Cancillería, reg. 192, f. 52. El privilegio exime a los aldeanos de contribuir junto con la villa, reconociéndoles el derecho de hacerlo por separado.

12 Archivo Municipal de Daroca (AMD), Pergaminos, 8.3; y confirmación de Martín I en 1405 (AMD, Pergaminos, 89.

13 Fueron cinco los sesmeros que actuaban como representantes de los aldeanos de cada distrito territorial o sesma. Corral (1987: 104) señala que la primera vez que aparecen en la documentación es en 1250, pero que posiblemente existían ya desde la fundación de la comunidad. Con el paso del tiempo fueron ganando atribuciones judiciales, muchas de ellas relacionadas con la tierra y sus diferentes usos agrícolas y ganaderos.

14 ACA, Cancillería, reg. 428, f. 196.

15 Campillo, 1915: 130, doc. 312.

16 Campillo, 1915: 142, doc. 342.

17 Rodrigo (2003) aborda el reflejo legal del incremento de la presión sobre pastos y montes en este período. 
Además de esta función de proponer adehesamientos que debían quedar autorizados posteriormente por el rey, los sesmeros fueron revestidos de capacidad jurídica para solucionar los conflictos entre vecinos por temas de bienes comunales, amojonamientos, términos, caminos, acequias, boalares, dehesas... así como para regular la manera en la que las dehesas debían ser explotadas mediante las actividades permitidas en ellas, estableciendo, por ejemplo, su cierre durante todo el año o su apertura en determinados meses. ${ }^{18}$ En 1270 quedaba prohibida expresamente la entrada de los ganados extranjeros, ya fuesen trashumantes o privilegiados, como era el caso de los rebaños zaragozanos. ${ }^{19}$ Ello entraba en colisión con otras decisiones regias y abría un conflicto directo con los pastores de la Casa de Ganaderos y con su derecho - reconocido por el monarca mediante emisión de privilegio_-, de ir a pacer por todos los montes situados dentro de los términos del reino.

Otro oficio fundamental por su rol dentro de las disputas que van a comentarse a continuación es el de vedalero ${ }^{20}$ o montero, también llamado guardamonte. Cuando en 1270 se estableció la forma en la que las dehesas y los boalares debían ser explotados, se ordenó que cada aldea tuviese dos guardamontes. Ellos eran los encargados de velar por que se respeten las normas establecidas para las dehesas, boalares y montes en general, denunciando a quienes las infringían (Campillo, 1915: 41, doc. 28). Los zaragozanos estuvieron siempre muy atentos a que fuesen los vedaleros quienes prendían a sus pastores, alegando en caso contrario que el acto era nulo e ilegal.

\section{Aproximación a los conflictos ganaderos de la Comunidad de aldeas de Daroca en la Baja Edad Media}

Los enfrentamientos entre agricultores y ganaderos han sido una constante a lo largo de la historia. En los siglos medievales, el derecho consuetudinario oral se recogió y complementó por escrito como parte del proceso de desarrollo y consolidación de las formaciones políticas feudales de la Euro-

18 Archivo Histórico Nacional (AHN), Diversos, Comunidades, carpeta 43, n. ${ }^{\circ} 2$

19 AMD, Pergaminos, 89.

20 Según Líbano y Villacorta, la variante 'vedalero' — derivada de 'vedado,' — es propiamente aragonesa, con un significado similar al de montero, guardián y vigilante de los bosques, y designa al vigilante del vedado, con responsabilidad para controlar las «entradas y salidas de los rebaños y supervisar si fuera necesario los malos usos de los pastos.» (Líbano y Villacorta, (2013: 37-138). En el ámbito darocense aparece la variante 'vezadero' (Rodrigo, 2000: 727). 
pa cristiana. En el caso aragonés, desde el siglo XI, los sucesivos ordenamientos legales - desde los primitivos fueros locales y privilegios reales hasta la posterior compilación foral y la actividad legislativa de las Cortes-, aludieron a las obligaciones y derechos de unos y otros. La reiteración de fueros, ordenanzas y normativas durante todo el período medieval en regular diversos aspectos de la economía agropecuaria evidencia que la conflictividad generada fue continua y de difícil resolución (Rodrigo, 2003: 80). Diversas legislaciones, pactos y acuerdos que se han conservado - ya desde el fuero de 1142 y las primeras ordenanzas de la Comunidad darocense de 1256- insisten en que los ganaderos, sean de donde sean - no provocasen daños en el pan ni en el vino.

Además de las tensiones intravecinales por los daños causados en los cultivos que ponen en evidencia las normativas y sistemas de guarda locales ${ }^{21}$ también hubo enfrentamientos entre los vecinos de distintos pueblos de la comunidad, siendo por lo general el sesmero el encargado de mediar entre unos y otros y tomar las decisiones adecuadas. Por ejemplo, en 1474 un ganadero de Villareal denunció a los de Villafranca del Campo porque dos años antes habían apedreado a su pastor y se llevaron dos ovejas en prenda (Fernández, 1993: 137). Rara vez se recurrió al rey, al menos hasta finales del siglo XV. Una excepción la encontramos en 1332, cuando los vecinos de Herrera de los Navarros se quejaron al monarca de que los pastores de Luesma estaban entrando en sus boalares, aparentemente con el permiso del procurador del rey, yendo así en contra de los estatutos (Campillo, 1915: doc 307).

Frecuentes fueron también las disputas entre los habitantes de Daroca y los de la comunidad, aunque en este caso hay que comprender que no sólo se luchaba por la explotación de la tierra en sí sino, sobre todo, por perpetuar la jurisdicción que Daroca había tenido sobre las aldeas. A medida que éstas compraban privilegios al rey, la villa perdía una parcela de poder sobre ellas y algunas prerrogativas fundamentales, como el derecho a pacer en sus montes. De acuerdo con una sentencia arbitral de 1442, los carniceros de Daroca podían llevar a sus animales a los ademprivios — terrenos comunes de pastu-

21 La situación de competencia entre agricultores y ganaderos resulta evidente en la mayor parte de los fueros y estatutos locales. La protección de la producción agrícola que sostiene a los pobladores hizo que las disposiciones abordasen las intromisiones en cultivos y estableciesen un sistema de guarda de las tierras cultivada a la par que se gestionó la creación de dehesas y boalares que asegurasen el alejamiento del ganado, fundamentalmente, de los campos de cereal y de vid. (Rodrigo, 2003: 80). 
$\mathrm{ra}^{22}$ - de las aldeas vecinas, siguiendo el principio de la alera foral. Sin embargo, en 1500 se inició un proceso a instancia de un carnicero de Daroca que acusó a los vecinos de Orcajo de no haberle dejado entrar a pacer en sus términos, a pesar de tener derecho a ello. ${ }^{23}$ La toma de ganado en calidad de prendas o penyoras también fue una habitual manifestación de la conflictividad cotidiana en el ámbito ganadero entre aldeanos y vecinos de Daroca (Rodrigo, 2000: 640).

Otro aspecto conflictivo entre las aldeas y Daroca fue la llegada de ganados castellanos a las ferias de la villa. Estas expediciones transitaban amparadas por el privilegio de feria y provistas de cartas de guiaje que permitían la libre circulación tanto a la ida como a la vuelta de la reunión comercial. Sin embargo, los aldeanos de las poblaciones más cercanas a las fronteras castellanas vieron en estos trasiegos la oportunidad de sacar algún rédito económico asaltando y prendando a ganaderos del reino vecino bajo el pretexto de que habían entrado ilegalmente a pastar en sus términos. También los ganaderos castellanos buscaron la excusa de la celebración de ferias para, sin tener guiajes, invadir las tierras circunvecinas. Estos conflictos acabaron en rápidos procesos judiciales sustanciados ante el Justicia de Daroca, como el protagonizado en 1431 por Joan Gil, un vecino de Santed, acusado falsamente de asaltar y prendar a Joan Ferrandez de Manzanares y a otros ganaderos castellanos de caprino y ovino que acudían a la feria de septiembre de Daroca (Rodrigo, 2000: doc.270).

Un tercer nivel de enfrentamiento se dio entre la Comunidad de aldeas de Daroca y otros territorios de la Extremadura aragonesa, especialmente con la vecina y limítrofe Comunidad de aldeas de Teruel. Así, se conserva la sentencia de 1342 correspondiente a un pleito por cuestiones de límites y en el que determinados abrevaderos, dehesas y boalares fueron uno de los ejes del conflicto entre ambas comunidades aldeanas. ${ }^{24}$ En 1400 los ademprivios fueron, de nuevo, motivo de una disputa en la que el procurador de la reina Violante de Bar, Berenguer de Bardají, ordenó a los representantes turolenses que no realizasen procedimiento alguno contra los de Daroca y trabajasen por solventar cualquier debate o cuestión suscitada por los terrenos limítrofes de pasto. ${ }^{25}$

22 Ver en nota 7 la referencia realizada por Líbano y Villacorta, 2013.

23 Para profundizar en este proceso judicial, ver Pardillos, 2006.

24 Archivo Histórico Provincial de Teruel (AHPTE), Comunidad de Aldeas, Pergaminos, 3/68.

25 AHPTE, Comunidad de Aldeas, Cartas, 18/1209. Tres años antes se había solventado otro pleito por el apresamiento del ganado de Torrecilla, aldea de Daroca, por parte de un montero de la Comunidad de 
Pero de mucha mayor trascendencia, duración e intensidad fueron los conflictos generados con la principal institución pecuaria aragonesa, la Casa de Ganaderos de Zaragoza. ${ }^{26}$ Los primeros pleitos de los que tenemos constancia datan de las dos últimas décadas del siglo XIV ${ }^{27}$ aunque fueron cada vez más frecuentes en la centuria siguiente. La escalada de la tensión entre ambas instituciones fue tal que ambas partes solicitaron la intervención de la monarquía para poner fin a tantas disputas.

Ya en 1407 Martín I concedió un privilegio - hoy perdido - a la comunidad darocense por el cual se permitía a los oficiales de la misma prendar a los pastores zaragozanos que entrasen con sus ganados dentro de los límites de la Comunidad de aldeas de Daroca. El privilegio contemplaba multas de 1000 florines de oro a los infractores, una cantidad muy importante de dinero que indica, sin duda, la firme voluntad regia de atajar tales intromisiones y evitar conflictos mayores. ${ }^{28}$

A pesar de ello, este privilegio no debió tener la eficacia perseguida: en 1414 el rey ordenó de nuevo a los zaragozanos, así como a los pastores y ve-

Teruel, Archivo de Mosqueruela, Pergamino de fecha 25/05/1397; y unos años más tarde, en1404, una carta de protesta nos informa de unos cobros indebidos de montazgo por parte de Teruel a unos vecinos de la aldea darocense de Singra (Archivo de Mosqueruela, carta de fecha 02/04/1404.

26 Aunque también hubo pleitos de los ganaderos zaragozanos con las otras tres comunidades de aldeas, su número es menor. Gerbet (2003: 142) señala que los zaragozanos no debieron de frecuentar esas tierras, algo que debe ser matizado. Sí que lo hicieron asiduamente, al menos hasta comienzos del siglo XIV, pero tal vez el hecho de que desde 1259 Teruel contase con un ligallo — que defendió fervientemente los pastos tanto de la ciudad como de la comunidad de aldeas a partir de su creación en 1277- favoreció que los zaragozanos decidieran marcharse hacia Daroca para evitar tanto conflicto. (Abad, 2004). Canellas recoge abundantes documentos en los que la monarquía y los jurados de Zaragoza intervienen a comienzos del siglo XIV a favor de Casa de Ganaderos, obligando a la villa y aldeas turolenses a respetar los privilegios de los zaragozanos en relación con el aprovechamiento de pastos y abrevaderos, quedando sin validez el amparo buscado por los turolenses en su propia foralidad: Canellas, 1988, docs. 22 (1295), 29 (1300), 33 (1301), 38 (1307), 43 (1309); no obstante, los conflictos continuaron a lo largo del siglo XIV y XV tanto con la comunidad de Teruel como con la de Albarracín: Canellas, 1988, docs. 98 (1369) y 139 (1415); esta última villa y su comunidad vieron revocado en 1420 por Alfonso V el privilegio recibido de Fernando 1 en 1415 sobre la autorización de constituir un ligallo (Canellas, docs. 131 y 135). Sorprendentemente, la comunidad darocense no logró tener un ligallo de ganaderos hasta 1542, con lo que quedó en situación de mayor desamparo durante los siglos XIV y XV frente a Casa de Ganaderos que los ganaderos de serranías turolenses.

27 Ya se ha hablado con anterioridad de cómo el declive demográfico y la reorganización de los patrones de poblamiento generaron amplias zonas de pastos que pronto captaron la atención de los ganaderos zaragozanos. Además, no hay que perder de vista que en ese momento se estaba produciendo un auge en la exportación de lana de Zaragoza tanto dentro como fuera de la Península Ibérica. (Sarasa y Sesma, 1978; Melis, 1990).

28 Conocemos la existencia de ese privilegio gracias a una mención del mismo en un documento de 1441 (Campillo, 1915: 230, doc 615). 
cinos de las otras comunidades de aldeas, que se guardasen de entrar en las dehesas y boalares de la comunidad de Daroca, puesto que contaban con un privilegio que lo prohibía expresamente y que había sido sancionado por los sucesivos monarcas. ${ }^{29} \mathrm{El}$ auge de las cabañas ganaderas de estos lugares y la escasez de pastos y hierbas en sus tierras de origen impulsaba a los ganaderos a enviar a sus pastores a la región de Daroca desafiando prohibiciones y multas que, a la vista de los acontecimientos, no resultaron disuasorias. Quizá las apelaciones y recursos judiciales a diversas instancias evitaron la ejecución de las sanciones y abrieron otras vías de solución. ${ }^{30}$

Setenta años más tarde tuvo lugar un plegamiento et concordia entre la Comunidat de Daroqua e la Casa de Ganaderos (Fernández, 1993: 137-138). El documento confirma que los enfrentamientos por la invasión de dehesas y boalares continuaron siendo habituales a lo largo del Cuatrocientos. Tantos años de pleitos tuvieron que generar no sólo una creciente tensión social sino, sobre todo, un pesado desembolso económico, con un continuo deterioro de las finanzas aldeanas. De ahí que los intentos por establecer acuerdos y concordias se multiplicasen en las últimas décadas del siglo XV, aunque los resultados de cada nuevo pacto siguieron siendo tan infructuosos como los firmados hasta entonces.

El último conflicto antes de la sentencia arbitral de 1501 es un proceso abierto en 1500 por parte de la Casa de Ganaderos y la villa de Longares - dependiente de la ciudad de Zaragoza - contra las comunidades de aldeas de Daroca y Albarracín. ${ }^{31}$ Los problemas giraban en esas fechas en torno a tres ejes: la jurisdicción del Justicia de Ganaderos, las dehesas antiguas y los pastores que no eran vecinos de Zaragoza pero que, del mismo modo que hacían los zaragozanos, llevaban sus ganados a las tierras de la Extremadura aragonesa.

Con respecto a las prerrogativas jurisdiccionales de la Casa de Ganaderos, ya hemos señalado que desde 1129 los habitantes de Zaragoza —y no

29 AMD, Pergaminos, $n^{\circ} 95$ (20/11/1414): Privilegio real por el cual Fernando I confirma los usos y costumbres de la Comunidad de aldeas de Daroca sobre aprovechamiento de pastos.

30 Archivo de la Fundación Casa de Ganaderos (FCG), Caja 53, ligamen 16, 2/2.: Proceso de firma de derecho de Casa de Ganaderos ante el Justicia de Aragón para que proceda contra oficiales darocenses por realizar pignoras.

31 Consta de tres partes, conservadas en el Archivo de la Fundación Casa de Ganaderos (FCG): Caja 430, Ligamen 203, 1; Caja 432, Ligamen 204, 1; Caja 436, Ligamen 205, 9 . Todos están digitalizados y disponibles en el portal DARA (Documentos y Archivos de Aragón): http://dara.aragon.es/opac/app/home/ 
solamente quienes poseían ganado-, gozaban del derecho de prender y juzgar en la ciudad a cualquier persona que les agraviase, siempre que dicho perjuicio se cometiese dentro de las tierras de realengo. Por su parte, el Justicia de Ganaderos tuvo desde 1218 la jurisdicción civil y criminal con la que poder enjuiciar a cualquiera que atentase contra los privilegios de los pastores y ganaderos zaragozanos. Para agilizar más los trámites, los acusados no tenían derecho a ser defendidos por abogados o procuradores, lo que garantizaba una sentencia a favor de los zaragozanos en la mayor parte de las ocasiones. Los cofrades defendían que su Justicia tenía este poder en todas las tierras de realengo, algo con lo que los afectados no estuvieron de acuerdo dando lugar a numerosas disputas y reclamaciones de índole jurisdiccional.

El tema de las llamadas 'dehesas antiguas' es más complejo y a la larga siguió provocando muy diversos conflictos, ya que quedó abierto a la interpretación del privilegio de la pastura universal. Recordemos que en 1129 los zaragozanos obtuvieron el permiso del rey para poder apacentar sus ganados en los montes reales que estuviesen dentro del extenso término municipal de la ciudad. La situación se complicó en 1235, cuando Jaime I hizo extensible este derecho a todos los montes y tierras de realengo de Aragón, llevando así los límites físicos de este privilegio mucho más allá del alfoz de Zaragoza; no obstante, el monarca se reservaba para sí el uso y disfrute de dos dehesas antiguas: Sigena y La Retuerta de Pina. Todo esto entraba en conflicto directo con el privilegio otorgado a los vecinos de la Comunidad de aldeas de Daroca, según el cual solamente ellos podían disfrutar de sus dehesas y boalares. Ante las continuas infracciones de los zaragozanos y para dar más legitimidad a sus reivindicaciones, los darocenses defendieron que sus dehesas también eran antiguas y que, por tanto, debían ser respetadas al igual que las de Sigena y Retuerta de Pina, argumento que los de Zaragoza nunca aceptaron.

Por último, la complejidad de la situación se acentuaba con el hecho de que fueron frecuentes los pastores que trabajaban para los ganaderos zaragozanos pero que no gozaban del estatuto de vecindad de la ciudad, circunstancia ésta que, en teoría, les impedía disfrutar del privilegio de la pastura universal. Los aldeanos elevaron sus quejas en reiteradas ocasiones alegando que ello suponía una violación todavía más flagrante de sus derechos; sin embargo, el asunto de los pastores foranos no parecía preocupar o molestar a los cofrades zaragozanos de San Simón y San Judas. 


\section{La sentencia de 1501}

Tras llegar a un consenso en 1500, las partes implicadas en el proceso decidieron recurrir al rey con el objetivo de que emitiese una sentencia arbitral. Antes de mediados del siglo XV este recurso al arbitrio real era una practica poco habitual; sin embargo, se hizo cada vez más frecuente a medida que los pleitos, con sus correspondientes dilaciones legales, se enquistaban sin solución generando malestar y tensión social. Y tanto reyes como reinas promocionaron y participaron activamente en la mediación y arbitraje para solventar conflictos de muy diversa índole, entre ellos los pleitos ganaderos (Pardillos, 2006; Gómez, 2012; García Herrero, 2015).

El 29 de marzo de 1501 se firmó dicha sentencia en Ronda y fue entregada un par de meses después, el 27 de mayo, a Domingo Spanyol y Pedro Lalueça, notarios públicos de Zaragoza. Se conservan dos copias, la primera en el Archivo de la Casa de Ganaderos ${ }^{32}$ y la segunda en el fondo de la Comunidad de aldeas de Daroca, dentro de la sección Diversos del Archivo Histórico Nacional. ${ }^{33}$

El primero de los conflictos se debe a la cuestión de la jurisdicción del Justicia de ganaderos. Mientras que los de Zaragoza alegaban que su Justicia podía intervenir en todas las tierras de realengo dentro del reino, los de Daroca y Albarracín defendían que esto no era cierto, ya que su poder se limitaba al término de la ciudad. Además, acusaban al Justicia de ser parcial en los juicios, ya que «sin oyr partes y sin processo, condena por solo dicho con juramento del pastor» (zaragozano, se sobreentiende), por lo cual se consideraban muy agraviados. Puesto que el tiempo que el rey tenía para emitir la sentencia era limitado, y juzgando que no estaba suficientemente informado de esta cuestión, sentenció que mientras investigaba mejor el asunto, el Justicia de ganaderos podría seguir ejerciendo su legítima jurisdicción, pero sobreseer «en reintegras fechas y facederas». De este modo, el monarca esperaba rebajar un poco la presión entre ambas partes.

Con respecto a las disputas por las dehesas antiguas, los de la comunidad darocense se quejaban de que los pastores de la Cofradía de San Simón y Judas no las respetaban, aun sabiendo que estaban protegidas por privilegio real

32 FCG, Caja 252, Ligamen 138, 28-2. Digitalizado y disponible en dara.aragon.es

33 AHN, Diversos, Comunidades, Car. 44, doc. 56. Digitalizado y disponible en http://pares.culturaydeporte.gob.es/inicio.html 
como ya se ha visto. Además, las presentaron como antiguas para dotarlas de mayor protección, algo con lo que los de Zaragoza no estuvieron de acuerdo. De hecho, los zaragozanos reclamaron poder apacentar y disfrutar de todos sus derechos, puesto que contaban con un privilegio de pasto por todos los montes del reino. Fernando II volvió a considerar que no sabía lo suficiente del tema ni cuáles eran las dehesas antiguas que poseía la Comunidad. Por ello, encargó a Domingo Agustín, lugarteniente del baile y a Jayme de la Cavallería, lugarteniente del maestre racional, que fuesen a averiguar qué dehesas poseía cada una de las aldeas, si son «antiguas antes del dicho privilegio del rey don Jayme o si son despues fechas, y como y con que auctoridad las han hecho y si son necessarias para cada una de las dichas aldeas»». ${ }^{34}$ Para ello les concedió un plazo de tres meses desde la recepción de la sentencia. Aunque el rey reconoció los privilegios de Alfonso I y de Jaime I que otorgaban a los zaragozanos la pastura universal, «salbando pan y vino y exceptadas las dehesas antiguas de la dicha Comunidad y sus aldeas», establecía que, hasta que el trabajo de averiguación estuviese hecho, los de Zaragoza no podrían entrar en ninguna de las dehesas de la Comunidad.

El problema de los pastores que no eran vecinos de la ciudad tampoco pudo solucionarse en ese momento. Por tercera vez, el monarca estableció que antes de emitir una sentencia era necesario informarse convenientemente. Para ello envió a sus oficiales a averiguar quiénes eran los pastores que trabajaban para los ganaderos de la Cofradía, si efectivamente eran vecinos o no de la ciudad y el tamaño de sus rebaños, algo que también causaba molestias en ambas comunidades de aldeas, que se quejaban de que eran demasiado numerosos y que estaban perjudicando enormemente a sus propios ganados.

Dentro de la sentencia hay un apartado específico para los conflictos por derechos de pasto entre las localidades de Longares ${ }^{35}$ y de Cariñena; en realidad, con la Comunidad de aldeas de Daroca en general. Los de Longares arguyeron que, a pesar de haber establecido en el pasado algunos pactos para poder apacentar sus ganados en los pastos de Cariñena, los de esta villa les vetaban la entrada. Por su parte, los de Cariñena negaron la existencia de cualquier tipo de acuerdo, algo que la comunidad darocense confirmó. El monarca se considera-

34 Ordenó hacer lo mismo con las dehesas de la Comunidad de aldeas de Albarracín, molesta también con los abusos de los ganaderos zaragozanos.

35 Se conserva un proceso judicial de 1479 entre los jurados de Zaragoza y la Comunidad de Aldeas de Daroca motivado porque los vecinos de Cariñena tomaron ganado en prenda a los de Longares (Archivo del Ayuntamiento de Zaragoza, Procesos, Caja 7284). 
ba de nuevo incapaz de emitir un juicio inmediato sobre el tema, así que hasta que se viese capaz de ello, ordenó que todo siguiese como hasta ese momento y que ambas partes se guardasen de causar daños y perjuicios a la otra.

Es posible que el conflicto entre estos dos lugares gire en torno a la pardina de Lagunas, un pueblo abandonado, como tarde, a comienzos del siglo XV y que estaba situado entre ambos términos..$^{36}$ Recordemos que cuando una aldea quedaba deshabitada, el término se transformaba jurídicamente en pardina y se arrendaba a alguna población vecina a cambio de una suma de dinero que iba a parar a las arcas de la Comunidad. ${ }^{37}$ Resulta curioso que en el caso de Lagunas no empezase a ser arrendado por Cariñena hasta 1703. Dada la ausencia de investigaciones centradas en este tema, resulta imposible saber la causa. ¿Estaba anexionada de manera ilegal a Cariñena, como sucede con otras pardinas aragonesas? ¿Lo estaba de manera legal, pero se ha perdido - 0 todavía no se ha localizado - la documentación que lo acredita? ¿Estaba arrendada a Cosuenda, la única aldea de la Comunidad, junto con Cariñena, que limitaba con Lagunas? En todo caso, visto el celo con el que la Comunidad guardaba sus dehesas y pastos, resulta complicado creer que existiese un pacto entre Cariñena y Longares, puesto que la primera contaba con la pardina de Lagunas para apacentar a sus rebaños y no tendría necesidad de traspasar los límites de la Comunidad para ir hasta los pastos de Longares. Tampoco parece probable que lo hiciese a cambio de una cantidad determinada de dinero, ya que seguramente aparecería mencionado como causa de peso para probar la existencia del pacto.

La sentencia arbitral resulta llamativamente ambigua, puesto que el monarca no se pronunció de manera firme sobre ninguno de los temas abordados. No es de extrañar, sin embargo, puesto que la villa de Longares y las comunidades de aldeas de Daroca y Albarracín eran vasallas suyas y la Casa de Ganaderos una institución muy poderosa en el ámbito territorial regnícola. Es posible que el monarca buscara algo de tiempo para ser lo más justo que pudiese y ofender con su dictamen lo menos posible a cualquiera de las cuatro partes implicadas en el proceso.

A pesar de ser tan poco resolutivo, el rey no se privó de imponer un elevado precio como pago de la realización de la sentencia, que recayó principal-

36 Para saber más sobre este despoblado, Iranzo y Ortega (2011).

37 No se conservan datos para la Edad Media pero sí algunos para la Edad Moderna. Para más información, ver Diarte, 1993: 407. 
mente en la Comunidad de aldeas de Daroca. A él hubo que darle un par de guantes, pagaderos a partes iguales por cada una de las cuatro partes implicadas. Las remuneraciones de todos los que habían intervenido directa o indirectamente en la elaboración del documento ascendió a 2700 sueldos, sin contar con el salario debido a Gil Spannol, encargado de redactar el proceso de 1500 y que todavía no había tasado su trabajo. Ese monto se dividió en cinco partes, cuatro de las cuales debían ser abonadas por la Comunidad de aldeas de Daroca y la quinta por la Casa de Ganaderos, villa de Longares y Comunidad de aldeas de Albarracín a partes iguales. Además, debía de pagarse en un plazo de 15 días desde la recepción de la sentencia arbitral.

A la vista de la dinámica de resolución del conflicto, resulta poco sorprendente saber que esta sentencia arbitral no fue respetada. Los litigios continuaron, especialmente aquellos relacionados con el tema de las dehesas antiguas y los pastores que no eran vecinos de Zaragoza. Se volvieron a abrir nuevos procesos hasta que en 1559 se firmó una concordia — que no sería terminada y promulgada hasta un año después - que pretendía poner fin, de una vez por todas, a los enfrentamientos entre la Comunidad de aldeas de Daroca y la Casa de Ganaderos. ${ }^{38}$

Por ella sabemos que los de Zaragoza acusaban a los de la Comunidad no solamente de hacer nuevas dehesas tras la promulgación de la sentencia algo que parece prohibido, aunque no se menciona en ningún momento- sino además de ampliar las que ya tenían. En dicha concordia se afirma que no queda claro si los enviados del rey nunca llegaron a hacer su trabajo o si los documentos fruto del mismo se perdieron. En cualquier caso, nadie estaba seguro de cuáles eran las dehesas antiguas de la Comunidad, aunque los ganaderos de Zaragoza seguían sin considerar justo que no pudiesen aprovechar sus pastos, fuesen antiguas o no.

Tampoco se había solucionado la cuestión de los pastores que no eran vecinos de Zaragoza. Desde el siglo XIII y hasta la promulgación de la concordia fue habitual que los oficiales de la Casa de Ganaderos visitasen los lugares en los que tenían previsto que sus empleados fuesen a apacentar los ganados, para presentar los privilegios de la cofradía a los habitantes del lugar (Pascua, 2012: 219). A partir de 1560, los pastores que quisieran partir hacia tierras de

38 Se conservan dos copias de la misma, la primera en el Archivo Municipal de Daroca (AMD, 23.16) y la segunda en la Casa de Ganaderos (FCG, Caja 45, Ligamen 210, 2). Actualmente se encuentra en fase de transcripción. 
la Comunidad debían presentarse ante el Justicia de ganaderos, probar que eran vecinos de la ciudad y declarar el tamaño de su rebaño. De este modo, antes del 8 de mayo de cada año se enviaba a unos mensajeros para que entregasen en las aldeas el listado de los pastores que se presentarían en sus términos y el tamaño de los rebaños que llevaban con ellos.

Resulta redundante decir que, una vez más, este acuerdo no supuso el fin de los enfrentamientos entre estas dos poderosas instituciones.

\section{Conclusiones}

La expansión del Reino de Aragón hacia el sur con el fin de conquistar las tierras en manos de los musulmanes permitió obtener nuevos y extensos territorios que, por sus características orográficas, fueron muy favorables para el ejercicio de la actividad ganadera. Además de la ganadería estante, se practicó la trashumancia corta, principalmente entre el Valle del Ebro y las zonas montañosas de los Pirineos y del Sistema Ibérico.

Los ganaderos de la Cofradía de San Simón y Judas de Zaragoza obtuvieron a lo largo del tiempo importantes privilegios que hacían de ella una asociación muy poderosa, lo que provocó el recelo y la antipatía allá donde fueran sus pastores. Aunque al principio los ganados zaragozanos frecuentaron las tierras de Albarracín y Teruel, los continuos conflictos con las villas y aldeas de las estribaciones del Sistema Ibérico promovieron un temprano interés por los aprovechamientos ubicados en la región ocupada por la Comunidad de aldeas de Daroca. Pero los vecinos de estas tierras tampoco estaban dispuestos a que los zaragozanos pisotearan sus derechos, principalmente los relacionados con el uso de pastos y dehesas.

Los pleitos fueron cada vez más numerosos y la tensión entre ambas instituciones fueron en aumento, lo que sumado a la ingente cantidad de dinero que ambas partes tuvieron que desembolsar en cada juicio, llevó a buscar la intervención del monarca como mediador y pacificador, de modo que emitiese una sentencia arbitral que pusiese fin a unas tensiones que ya eran seculares. El 29 de marzo de 1501 Fernando II promulgó dicha sentencia — que también incumbía a la villa de Longares y a la Comunidad de aldeas de Albarracín-, pero sus contenidos no fueron respetados ni observados, generando nuevos enfrentamientos. El arbitraje real se requirió y se produjo pero, en la práctica, quedó sin efecto alguno. 


\section{Referencias bibliográficas}

AbAd Asensio, José Manuel (2004), «La trashumancia en la Comunidad de aldeas de Teruel (siglos XIII-XV): una valoración documental.» En José Luis Castán Esteban y Carlos Serrano Lacarra, coords., La trashumancia en la España mediterránea: historia, antropología, medio natural, desarrollo rural. Zaragoza, Rolde de Estudios Aragoneses: 177-202.

Agudo Romeo, María del Mar (1992), El fuero de Daroca: Introducción, edición crítica, traducción, estudio léxico y concordancia. Daroca-Zaragoza, Centro de Estudios Darocenses / Institución Fernando El Católico.

Agudo Romeo, María del Mar (2006), «Una concesión de Alfonso I el Batallador a Tudela: el denominado 'privilegio de los veinte' y los Fueros de Zaragoza.» En Navarra. Memoria e imagen. Actas del VI Congreso de Historia de Navarra (Pamplona, sept. 2006). Pamplona, Eunate. Vol 1: 95-108.

AlLUÉ ANDRÉS, Lidia C. (2018), «Dinámicas de poblamiento y población en un espacio de frontera: la Comunidad de Aldeas de Daroca (siglos XIII-XV)», Aragón en la Edad Media, 29: 25-68.

ARGUDO PÉRIZ, José Luis (1997), Servidumbres y mancomunidades de pastos en Aragón: antecedentes forales y estudio del artículo 146 de la Compilación de Derecho Civil de Aragón. Zaragoza, Prensas de la Universidad de Zaragoza (Tesis doctorales en línea).

ASSO Y DEL Río, Ignacio Jordán de (1983), Historia de la economía política de Aragón. Zaragoza, Guara. Edición facsimilar de la de Zaragoza, por Francisco Magallón, 1798.

BERGES SÁNCHEZ, Juan Manuel (2004), «Para una historia de las instituciones pastoriles en Aragón: la Mesta de Albarracín a través de sus ordinaciones.» En José Luis Castán Esteban y Carlos Serrano Lacarra, coords., La trashumancia en la España mediterránea: historia, antropología, medio natural, desarrollo rural. Zaragoza, Rolde de Estudios Aragoneses: 263-364.

BERGES SÁNCHEZ, Juan Manuel (2006), «De montes y pleitos: el patio del rey don Jaime», Rehalda. Revista del Centro de estudios de la Comunidad de Albarracín, 3: 39-44.

BERGES SÁNCHEZ, Juan Manuel (2009), Actividad y estructuras pecuarias en la Comunidad de Albarracín (1284-1516). Albarracín-Teruel, Centro de estudios de la Comunidad de Albarracín, Instituto de Estudios Turolenses.

CAmpillo CaSAmor, Toribio del (1915), Documentos históricos de Daroca y su Comunidad. Zaragoza, Imprenta del Hospicio Provincial.

CAnellas López, Ángel (1972), Colección diplomática del Concejo de Zaragoza. Zaragoza, «Cátedra Zaragoza»-Universidad de Zaragoza.

CANEllas LóPeZ, Ángel (1982), El Archivo de la Casa de Ganaderos de Zaragoza. Noticia e Inventario. Zaragoza, Institución Fernando El Católico. Col. «Fuentes Históricas Aragonesas», 8. 
CAnellas LóPeZ, Ángel (1988), Diplomatario medieval de la Casa de Ganaderos de Zaragoza. Zaragoza, Real Sociedad Económica Aragonesa de Amigos del País.

Corral Lafuente, José Luis (1987), La Comunidad de aldeas de Daroca en los siglos XIII y XIV: orígenes y proceso de consolidación. Zaragoza, Institución Fernando El Católico.

Diarte Lorente, Pascual (1993), La Comunidad de Daroca. Plenitud y crisis (15001837). Daroca- Zaragoza, Centro de Estudios Darocenses / Institución Fernando El Católico.

FALCÓN PÉREZ, Isabel (1981), «La ganadería aragonesa medieval.» En Agustín Ubieto Arteta, coord., Actas de las III Jornadas sobre el Estado actual de los estudios sobre Aragón celebradas en Tarazona del 2 al 4 de octubre de 1980. Zaragoza, Universidad de Zaragoza, Instituto de Ciencias de la Educación: 893-903.

FERnÁNDEZ OTAL, José Antonio (1993), La Casa de Ganaderos de Zaragoza. Derecho y trashumancia a fines del siglo XV. Zaragoza, Institución Fernando El Católico.

GARCÍA EDO, Vicent (2016) «El fuero de Zaragoza en el siglo XII (Aproximación a su estudio)», Revista de Dret Històric Català, 15: 165-197.

García Herrero, Carmen (2015) «María de Castilla, reina de Aragón (1416-1458): La mediación incansable», e-Spania, 20 (février, 2015).

GERBet, Marie-Claude (2003), La ganadería medieval en la Península Ibérica. Barcelona, Crítica.

GómEZ DE VALENZUELA, Manuel (2012) «Los tribunales arbitrales en Aragón en el siglo XV», Aragón en la Edad Media, 23: 143-172.

IrANZO MuÑío, M. ${ }^{\text {a }}$ Teresa y Julián M. ORTEGA ORTEGA (2011), «Disciplina agraria y reorganización del poblamiento bajomedieval en el territorio de la Comunidad de aldeas de Daroca.» Aragón en la Edad Media, 22: 67-127.

LíBAnO ZumalaCÁRregui, Ángeles y Consuelo Villacorta MACHO (2013), Paisaje rural y explotación agropecuaria: léxico de los recursos naturales y de la vida cotidiana en el aragonés, navarro y romance vasco, siglos XIII-XVI. Zaragoza, Prensas de la Universidad de Zaragoza.

MELIS, Federigo (1990), «La lana della Spagna mediterranea e della Barberia occidentale nei secoli XIV-XV.» En Federigo Melis, I Mercanti Italiani nell'Europa Medievale e Rinascimentale, Firenze, Istituto Internazionale di Storia Economica F. Datini: 233-250.

PARDILlos MARTín, David (2006), «Un pleito en torno a la explotación de las tierras de pastos en la Comunidad de aldeas de Daroca (1500).» Aragón en la Edad Media, 19: 433-442.

PASCUA ECHEGARAY, Esther (2012), Señores del paisaje. Ganadería y recursos naturales en Aragón, siglos XIII-XVII. Valencia, Publicacions de la Universitat de València.

Rodrigo-Estevan, María Luz (1999), La ciudad de Daroca a fines de la Edad Media. Selección documental (1328-1526). Daroca-Zaragoza, Centro de Estudios Darocenses, Institución Fernando El Católico. 
RODRIGO-ESTEVAN, María Luz (2003), «La explotación de los recursos naturales en la legislación aragonesa medieval.» En Iñaki Iriarte Goñi y Alberto Sabio Alcutén, editores, La construcción histórica del paisaje agrario en España y Cuba. Madrid, Los Libros de la Catarata: 71-96.

RoDRIGO-ESTEVAN, María Luz (2009), «Jaime I, Aragón y los aragoneses: reflexiones sobre un rey, un territorio y una sociedad.» En Esteban Sarasa Sánchez, coord., La sociedad en Aragón y Cataluña en el reinado de Jaime I: 1213-1276. Zaragoza, Institución Fernando El Católico.

SARASA SÁNCHEZ, Esteban, coord. (2009), La sociedad en Aragón y Cataluña en el reinado de Jaime I: 1213-1276. Zaragoza, Institución Fernando El Católico.

SARASA SÁNCHEZ, Esteban y J. Ángel SESMA MUÑOZ (1978), «El comercio de la lana por el Ebro hacia el Mediterráneo (El puerto fluvial de. Escatrón a mediados del siglo XV).» En II Congreso Internacional de estudios sobre las culturas del Mediterráneo occidental. Barcelona, Universidad Autónoma: 399-409.

PÉreZ-Soba DiEZ DEL CorRAL, Ignacio y Miguel Ángel SolÁ MARTín (2004), La alera foral de pastos en Aragón. Zaragoza, El Justicia de Aragón.

UTRILla UTRILlA, Juan Fernando, «La población de Calatayud y su Comunidad de aldeas ante la crisis demográfica del siglo XIV (1350-1414).» En José Ángel Sesma Muñoz y Carlos Laliena Corbera, coordinadores, La población de Aragón en la Edad Media (siglos XIII-XV). Estudios de demografía histórica. Zaragoza, Leyere: 403-467. 